\title{
INVESTIGATING DISSOLVED AIR FLOTATION FACTORS FOR OIL REFINERY WASTEWATER TREATMENT
}

\author{
Emmanuel Kweinor Tetteh ${ }^{1}$, Sudesh Rathilal ${ }^{2}$
}

\begin{abstract}
The global demand for petrochemical and petroleum industry products unavoidably generates large volumes of oil refinery wastewater (ORW). The complete treatment, reclamation and disposal of the ORW to an acceptable environmental limit is currently a challenge to most of the petroleum industries. With the current development in conventional treatment methods viz. coagulation, dissolved air flotation (DAF), and biological and membrane separation processes. DAF, which is well-established separation process, effectively employs microbubbles as a carrier phase for separation. Although, DAF is frequently used in combined water and wastewater treatment plants, its fundamental characteristics and operational parameters have not yet been fully investigated for the treatment of ORW. In this study, the correlation and effects of the parameters understudy (coagulant dosage, air saturator pressure, air-water ratio and rising rate) on chemical oxygen demand, soap oil and grease, turbidity and total suspended solids removal from ORW were examined experimentally using a laboratory DAF system. The results showed that increasing the saturator working pressure and the rising rate had less effect on the system, than increasing the air-water ratio. The agglomeration of the oil droplets was found to depend solely on the polyaluminum sulphate (PAS) dosage to destabilize the oil droplets. The DAF treatability performance showed over $80 \%$ removal of the contaminants at optimum conditions of $\mathrm{pH}$ of 5 , PAS dosage of $10 \mathrm{mg} / \mathrm{L}$, rising rate of 15 minutes, air saturator pressure of 300-500 kPa, and air-water ratio of 5-15\%. The PAS dosage was found to be the most significant factor. Therefore, a moderate increase of the PAS dosage under these optimum conditions will increase the DAF efficiency in the treatment of ORW.
\end{abstract}

UDC Classification: 502/504; DOI: http://dx.doi.org/10.12955/cbup.v6.1311

Keywords: Dissolved air flotation, DAF, flotation, oil refinery wastewater, oil from water

\section{Introduction}

The rational for wastewater treatment, water protection, conservation and reclamation for water usage are vital elements for water management. Since water management is a universal problem, effective ways of recovering it is very essential for both developed and underdeveloped countries(Pintor et al., 2015). In South Africa, the oil refinery industries have a very high specific water intake (SWI) compared to other industries like the textile, pharmaceutical and paint industries(Welz et al., 2007; ElNaas et al., 2016). From SWI between 0.51 and $0.67 \mathrm{~m}^{3} / \mathrm{t}$ crude, as much as $40 \%$ of this water is discharge as effluent into the municipal sewer system (Tetteh \& Rathilal, 2018). This wastewater is basic with high contents of soap oil and grease (SOG), organics and inorganics compounds and other pollutants, which are non-biodegradable; hence, treatment is essential before discharge(Diya'Uddeen et al., 2011). The amount of oil, which is the main component in oil refinery wastewater (ORW), has been strictly regulated by the South Africa legislation (The National Water Act, 1988).

Generally, most industrial wastewater treatment companies face the challenge to acquire effective treatment techniques to comply with the environmental regulations, conserve water and present opportunity for pollution reduction (Sahu \& Chaudhari, 2013). Currently, most research efforts are being dedicated to process development and optimization such as combination of physical, chemical and biological processes for the effective treatment of ORW(Yavuz et al., 2010; Guo et al., 2011). However, the use of biological processes for treatment of ORW is problematic, sincethe oil composition is not suitable for the growth of microbial community(Diya'Uddeen et al., 2011;Guo et al., 2011). Chemical treatment is also an essential pre-treatment requirement for the efficient treatment of ORW, since conventional flotation techniques for removing oils are not satisfactory without chemicals (Yavuz et al., 2010). The addition of the chemicals destroys the emulsifying agent and allows the oil droplets agglomerate to form larger sized ones through coagulation. The supportive physico-chemical treatment processes such as coagulation, electrocoagulation and flotation are frequently employed for the separation of oil from water (El-Naas et al., 2014; Yavuz et al., 2010).

Dissolved air flotation (DAF), is a gravity separation process very eminent in industrial-scale wastewater treatment. This process was first used in Scandinavia and South Africa for the treatment of portal water, and over the last 30 years, the applicability of DAF has escalated due to its effectiveness

${ }^{1}$ Faculty of Engineering and the Built Environment, Durban University of Technology, South Africa, ektetteh34@gmail.com

${ }^{2}$ Faculty of Engineering and the Built Environment, Durban University of Technology, South Africa, rathilals@dut.ac.za 
(Edzwald, 1995). DAF is coupled with an air saturator system, which generate small bubbles (10-100 $\mu \mathrm{m})$ serving as a driving force for the flotation process. Thus, the smaller the bubble size, the greater the bubble -oil droplet interfacial contact area to increase the process efficiency. The bubbles are usually generated by saturating the treated water with air, in an air saturator vessel under a moderate pressure of 300-600 kPa (Karhu et al., 2014; Edzwald, 1995). The difference between the operating pressure of the saturator and the outlet pressure in the flotation vessel is proportional to the volume of air injected into the system. The sudden reduction in the water stream through needle valves of distinct orifices stimulates the release of microbubbles as the main driving force on the oil droplet to move upward (Sahu \& Chaudhari, 2013; El-Naas et al., 2016) .

Over the past years, there have been dramatic improvements on the design and specification of DAF, with the view of improving water treatment (Aliff Radzuan et al., 2016).There are various types of DAF designs, viz. vacuum flotation, micro flotation and pressure flotation which depends on the mode of generating the microbubbles(Karhu et al., 2014;Diya'Uddeen et al., 2011). The design of specified DAF system depends on factors like the type and volume of the wastewater, the degree and nature of contaminants, appropriate pressure, flowrate, retention time, recycle ratio, coagulant type and dosage anticipated for the treatment. Despite the widespread acceptance and industrial application of DAF technology, some questions related to the optimization and functionality remain unanswered.

This study aims to investigate the interfacial effects of the chemical and the oil emulsion on a laboratory DAF unit, via the influence of coagulation, air bubble generation (air pressure and recycle ratio) and oil droplet-air bubble contact time.

\section{Materials and method}

Oil refinery effluent obtained from a local South African oil refinery plant was used for this study. The ORW sample was characterised in accordance with methods by Tetteh et al., (2017)and the American Public Health Association (APHA) standard method of examining wastewater(APHA, 2012). The initial chemistry of the ORW obtained werea $\mathrm{pH}-7$, SOG-1320 mg/L and TSS-1035 mg/L. Bench scale DAF jar test unitswereused; this was operated at a constant rapid mixing of $250 \mathrm{rpm}$ for two minutes followed by slow mixing at $30 \mathrm{rpm}$ for 15 minutes. The air saturator pressure regulator allowed the pressure to be investigated from $200-600 \mathrm{kPa}$, likewise the air-water ratio varied from 5$20 \%$. The coagulant dosage and flotation time were evaluated from $5-10 \mathrm{mg} / \mathrm{L}$ and $15-30$ minutes respectively. The polyaluminum sulphate (PAS) which was used as a coagulant,was supplied by Sigma Aldrich, South Africa.

\section{Results and Discussion}

The quantity of air to be injected into the system was varied from 200 to $600 \mathrm{kPa}$, with a sequence interval of $100 \mathrm{kPa}$. It was observed that the amount of air-water saturated was directly proportional to the microbubbles generated to the partial pressure applied. Thus, the best-fit curve for SOG and TSS coefficient of determination $\left(\mathrm{R}^{2}\right)$ were found to be $98.59 \%$ and $99.95 \%$ respectively .This relation is in agreement with Henry's Law.

$$
\mathrm{P}=\mathrm{KM}
$$

Where $\mathrm{P}, \mathrm{K}$ and $\mathrm{M}$ represents pressure, Henry's constant and molar concentration of the gas respectively.

Figure 1, shows tgesaturation pressure required to maximise the contaminant removal of over $80 \%$ wasfound to be $300-500 \mathrm{kPa}$. Such that an increase in pressure from 200 to $500 \mathrm{kPa}$ increased the contaminants removal. However, a further increase in the pressure from 500 to $600 \mathrm{kPa}$ brought no significant change to the system performance regarding the contaminant removal. This was because the air saturator pressure at some point showed no further change in the bubble size to cause the attachment and precipitation of the oil droplets for the oil-water phase separation (Karhu et al. 2014).

\section{Evaluation of air-water ratio}

It was observed that an increase in air-water flow above the theoretically required one had no significant effect in the generation of microbubbles. Figure 2 depicts a linear trend for SOG removal with an increased air-water ratio from 5-20\%, however, a further increase in air-water ratio beyond $15 \%$ resulted in a decrease in TSS removal. The best fit curve for SOG and TSS showed hyperbolic correlation with $\mathrm{R}^{2}$ values of $96.26 \%$ and $97.33 \%$ respectively. 

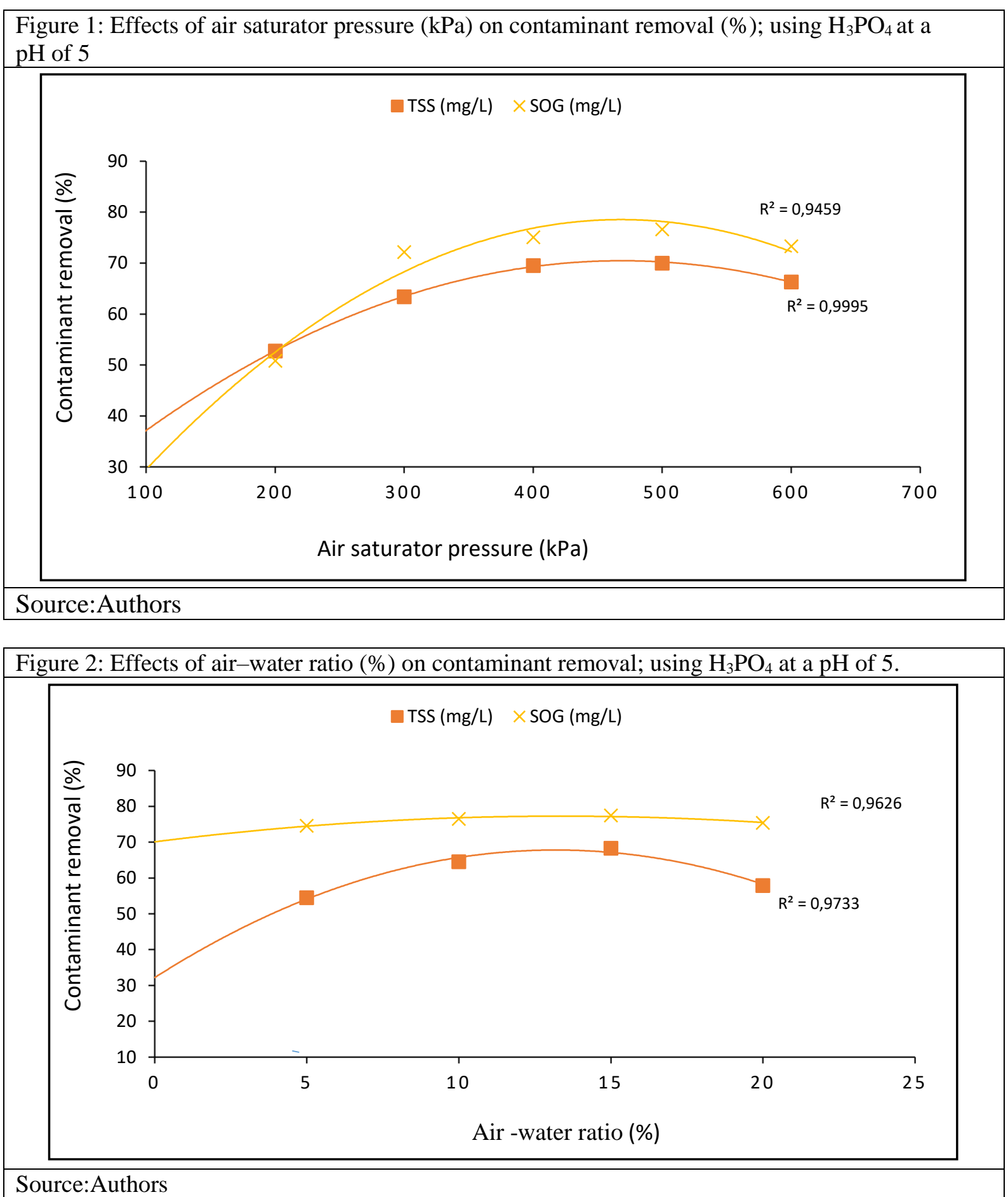

\section{Evaluation of coagulant dosage}

The coagulant (PAS) dosage was investigated at a lower range from 5 to $10 \mathrm{mg} / \mathrm{L}$, with a sequence increase of $1 \mathrm{mg} / \mathrm{L}$, to determine the PAS chemistry with the effluent. It was found that increasing the PAS dosage increased the nucleation rate of the contaminants via the adsorption principle hence increased the number of flocs growths in suspension. This increased the surface area of flocs on which adsorption of the SOG and the TSS occurred. On contrary, a low dosage of PAS led to fewer flocs, which resulted in a smaller surface area for the adsorption of the contaminants to occur. Figure 3, shows that increasing the coagulant dosage had a significant change in the contaminants removal. This led to good agglomeration and floatability of the oil droplets, and clarification of the treated water (Tetteh et al. 2017). The correlation between the coagulant dosage and the contaminant removal were well fitted with $\mathrm{R}^{2}$ values of $96.91 \%$ and $86.67 \%$ for SOG and TSS respectively. 


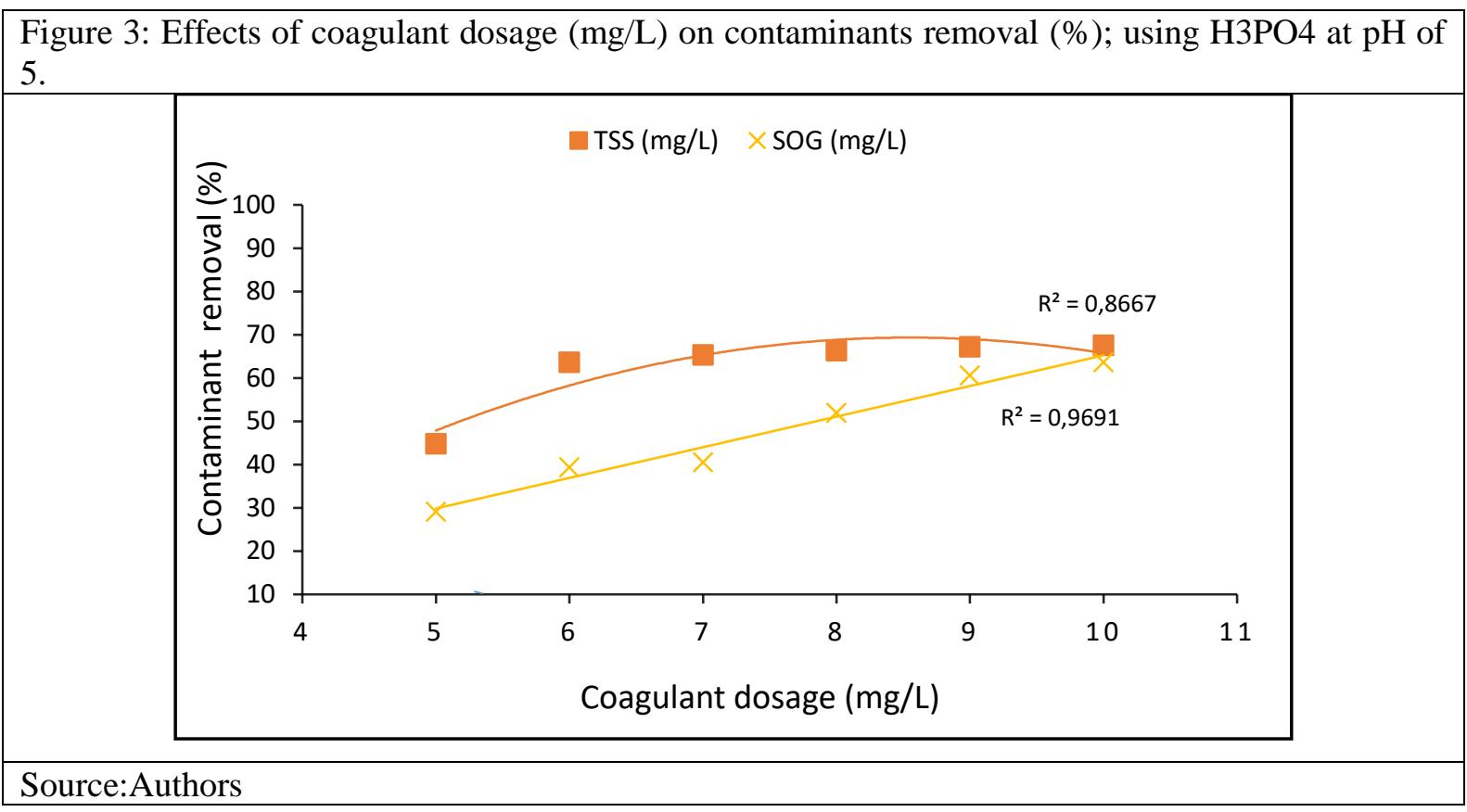

\section{Evaluation of flotation time}

The DAF performance in terms of flotation time is defined as a function of the contact time that exist between the air bubble and the oil droplet attachment. Figure 4 shows that an increase in retention time led to a lowering effect onbubble generation, hence decreasing the contaminants removal. This was because the oil droplet flocs which formed within that specific contact time might be exposed to disruption (floc shear stress) in the contact zone of the vessel. So, the flotation mechanism which was stimulated by air bubbles to adhere to the oil droplet flocs required a shorter time to rise to the surface(Yan et al., 2014).The correlation also showed a well fitted best fit curve withR ${ }^{2}$ values of $96.63 \%$ and $99.99 \%$ for SOG and TSS respectively.

Figure 4. Effects of flotation time (minutes) on contaminants removal (\%); using $\mathrm{H} 3 \mathrm{PO} 4$ at a $\mathrm{pH}$ of 5.

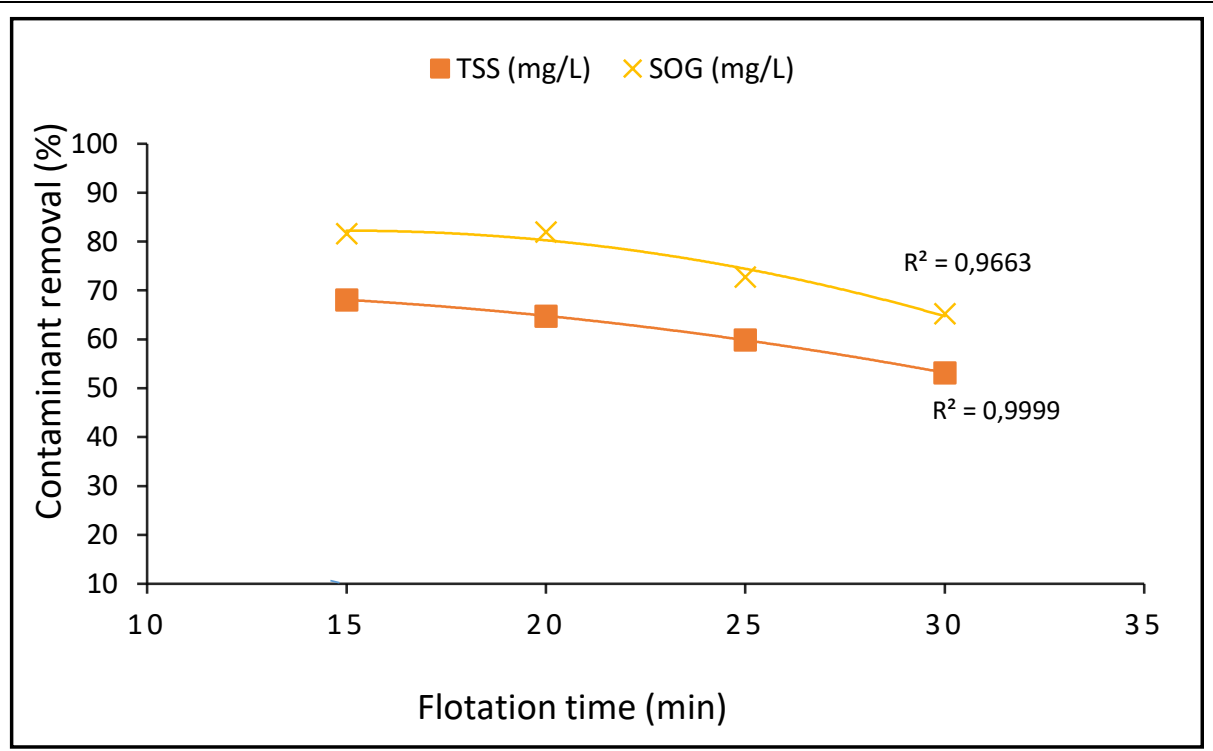

Source: Authors

\section{Conclusion}

DAF pre-treated with coagulant requires appropriate dosage to neutralize the oil droplet charge and simultaneously coalesce the oil droplets to improve the DAF efficiency. Consequently, the addition of the PAS reduced the electrostatic repulsion force of the oil emulsion to agglomerate which increased 
the DAF treatability performance. In addition, the bubble generation increased the interfacial surface area, which created an environment for effective oil droplet-bubbles attachment. Therefore, in this study the DAF efficiency is directly proportional to the bubble generation attributed to the air saturator pressure (300-500 kPa), air-water ratio (5-15\%), a binding force as PAS at a dosage of $10 \mathrm{mg} / \mathrm{L}$ and a $\mathrm{pH}$ of 5 .

\section{Acknowledgement}

We wish to thank Durban University of Technology for their sponsorship.

\section{Reference}

Aliff Radzuan, M. R., Abia-Biteo Belope, M. A., \& Thorpe, R. B. (2016). Removal of fine oil droplets from oil-in-water mixtures by dissolved air flotation. Chemical Engineering Research and Design, 115, 19-33. https://doi.org/10.1016/j.cherd.2016.09.013

APHA/AWWA/WEF. (2012). Standard Methods for the Examination of Water and Wastewater. Standard Methods, 541. https://doi.org/ISBN 9780875532356

Diya'Uddeen, B. H., Daud, W. M. A. W., \& Abdul Aziz, A. R. (2011). Treatment technologies for petroleum refinery effluents: A review. Process Safety and Environmental Protection, 89(2), 95-105. https://doi.org/10.1016/j.psep.2010.11.003 Edzwald, J. (1995). Principles and applications of dissolved air flotation. Water Science and Technology, 31(3-4), 1-23. https://doi.org/10.1016/0273-1223(95)00200-7

El-Naas, M. H., Alhaija, M. A., \& Al-Zuhair, S. (2014). Evaluation of a three-step process for the treatment of petroleum refinery wastewater. Journal of Environmental Chemical Engineering, 2(1), 56-62.

https://doi.org/10.1016/j.jece.2013.11.024

El-Naas, M. H., Surkatti, R., \& Al-Zuhair, S. (2016). Petroleum refinery wastewater treatment: A pilot scale study. Journal of Water Process Engineering, 14, 71-76. https://doi.org/10.1016/j.jwpe.2016.10.005

Guo, S., Li, G., Qu, J., \& Liu, X. (2011). Improvement of acidification on dewaterability of oily sludge from flotation. Chemical Engineering Journal, 168(2), 746-751. https://doi.org/10.1016/j.cej.2011.01.070

Karhu, M., Leiviskä, T., \& Tanskanen, J. (2014). Enhanced DAF in breaking up oil-in-water emulsions. Separation and Purification Technology, 122, 231-241. https://doi.org/10.1016/j.seppur.2013.11.007

Pintor, A. M. A., Martins, A. G., Souza, R. S., Vilar, V. J. P., Botelho, C. M. S., \& Boaventura, R. A. R. (2015). Treatment of vegetable oil refinery wastewater by sorption of oil and grease onto regranulated cork - A study in batch and continuous mode. Chemical Engineering Journal, 268, 92-101. https://doi.org/10.1016/j.cej.2015.01.025

Sahu, O. P., \& Chaudhari, P. K. (2013). Review on Chemical treatment of Industrial Waste Water Review on Chemical treatment. Journal of Applied Science Environmental Management, 17(2), 241-257. https://doi.org/http://dx.doi.org/10.4314/jasem.v17i2.8

Tetteh, E. K., \& Rathilal, S. (2018). Evaluation Of The Coagulation Floatation Process For Industrial Mineral Oil Wastewater Treatment Using Response Surface Methodology (rsm). International Journal of Environmental Impacts, 1(4), 491-502. https://doi.org/10.2495/EI-V1-N4-491-502

Tetteh, E. K., Rathilal, S., \& Robinson, K. (2017). Treatment of industrial mineral oil wastewater - effects of coagulant type and dosage. Water Practice and Technology, 12(1), 139-145. https://doi.org/10.2166/wpt.2017.021

Welz, M. L. S., Baloyi, N., \& Deglon, D. A. (2007). Oil removal from industrial wastewater using flotation in a mechanically agitated flotation cell. Water SA, 33(4), 453-458.

Yan, L., Wang, Y., Li, J., Ma, H., Liu, H., Li, T., \& Zhang, Y. (2014). Comparative study of different electrochemical methods for petroleum refinery wastewater treatment. Desalination, 341(1), 87-93. https://doi.org/10.1016/j.desal.2014.02.037

Yavuz, Y., Koparal, A. S., \& Öğütveren, Ü. B. (2010). Treatment of petroleum refinery wastewater by electrochemical methods. Desalination, 258(1-3), 201-205. https://doi.org/10.1016/j.desal.2010.03.013 